ANOVA) and tachycardia mean (SD) to 245 (44) bpm occurred at $140 \mathrm{~mL}$ instillation $(p=0.001)$.

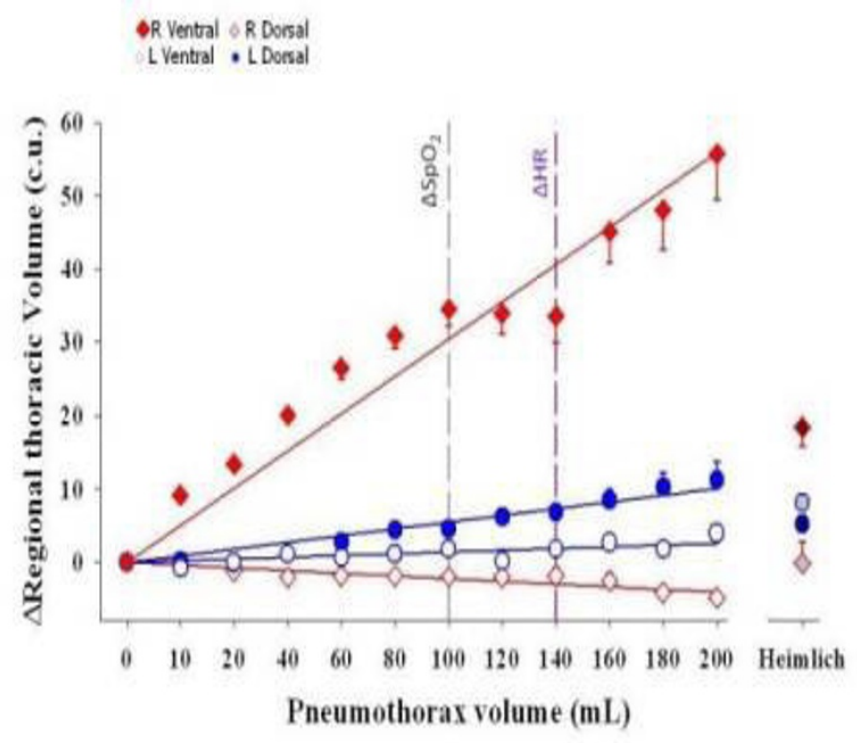

[Regional thoracic volume vs Pneumothorax size]

Conclusions: EIT accurately identified the location of even small volume pneumothoraces before physiological parameters changed.

\section{6 \\ HELIOX IN THE MANAGEMENT OF NEONATES WITH MECONIUM ASPIRATION SYNDROME (MAS)}

\section{T. Szczapa1, J. Gadzinowski ${ }^{1}$, J. Szczapa²}

${ }^{1}$ Department of Neonatology, ${ }^{2}$ Department of Neonatal Infectious Diseases, Poznan University of Medical Sciences, Poznan, Poland

The aim of the study was to asses the influence of short-term mechanical ventilation with heliumoxygen mixture (heliox) in newborns with MAS on basic vital signs, oxygenation, acid-base balance and respiratory mechanics.

The study was carried out in newborns with respiratory failure requiring mechanical ventilation due to MAS.Patients were ventilated using PC-SIMV. Parameters of mechanical ventilation,respiratory mechanics,oxygenation,acid-base balance and vital signs were recorded during three periods of one hour before,during and after heliox ventilation.

Nine newborns with MAS were enrolled in the study. Mechanical ventilation with heliox did not affect vital signs, and infants' general condition remained stable during and after ventilation with heliox. Mechanical ventilation with heliox was associated with a statistically significant increase in dynamic compliance(mean 0,4 vs $0,53 \mathrm{ml} / \mathrm{cmH}_{2} \mathrm{O}$ ). Heliox caused an increase in tidal volume(mean 5,57 vs $6,84 \mathrm{ml} / \mathrm{kg}$ ) and minute ventilation(mean 0,87 vs $0,95 \mathrm{I}$ )but this was not statistically significant. Mechanical ventilation with heliox allowed the use of significantly lower fractions of inspired oxygen(mean 0,62 vs 0,35 ), with a significant decrease in the oxygenation index(mean 8,09 vs 4,26)and alveolararterial oxygen tension difference(mean 320,04 vs $127,65 \mathrm{mmHg}$ ). A significant increase in $\mathrm{pH}$ (mean 7,34 vs 7,38 ) was also observed with a concomitant decrease in $\mathrm{PaCO}_{2}$ (mean 43,4 vs 39,9)which was not statistically significant.Beneficial effects of heliox reversed after ventilation with this gas mixture was stopped.Patients required higher $\mathrm{FiO}_{2}$ (mean 0,35 vs 0,38 ), $\mathrm{Ol}$ (mean 4,26 vs 5,27 )and $\mathrm{AaDO}_{2}$ (mean 127,65 vs 159,6)increased.There was also a significant decrease in oxygen saturation(mean $93,69$ vs 91,63$)$.

Ventilation with heliox had a positive effect on the selected parameters of oxygenation,acid-base balance and respiratory mechanics in newborns with MAS.

\section{7}

\section{VOLUME-TARGETED VENTILATION REDUCES THE RISK OF DEATH OR BPD: A COCHRANE META-ANALYSIS}

\author{
K.I. Wheeler ${ }^{1}$, C. Klingenberg ${ }^{1,2}$, N. McCallion ${ }^{3}$, \\ C.J. Morley ${ }^{1}$, P.G. Davis ${ }^{1}$
}

${ }^{1}$ Dept. of Newborn Research, Royal Women's Hospital, Melbourne, VIC, Australia, ${ }^{2}$ Dept. of Paediatrics, University Hospital of North Norway, Troms $\varnothing$, Norway, ${ }^{3}$ Neonatal Medicine, National Maternity Hospital, Dublin, Ireland

Background and aims: Volutrauma is associated with neonatal lung injury. Modern ventilators offer volume-targeted modes aiming to reduce volutrauma and improve $\mathrm{PaCO}_{2}$ stability. The objectives were to determine whether volume-targeted ventilation (VTV), compared with pressure-limited ventilation (PLV), reduces mortality, bronchopulmonary dysplasia (BPD) and other outcomes.

Methods: Cochrane systematic review of randomised clinical trials comparing VTV with PLV. Risk ratios (RR) or weighted mean difference with 